\title{
Tres momentos en las ideas sobre historia universal, antigüedad y civilización en el pensamiento de Olga Poblete, 1932-1962
}

\author{
Three moments in the ideas of universal history, antiquity, and \\ civilization in the thought of Olga Poblete, 1932-1962
}

Enrique Riobó Pezoa*

\section{RESUMEN}

El artículo busca caracterizar y explicar las transformaciones Palabras clave: en las ideas de "historia universal", "civilización" y "antigüedad" en la obra de Olga Poblete, entre 1932 y 1962. Con ello se busca analizar en profundidad un ámbito específico de la autora chilena hasta ahora poco estudiado. Se establecen tres momentos Olga Poblete, civilización, antigüedad, historia universal. diferenciados, los que marcan cambios en el pensamiento de Olga Poblete sobre historia universal, antigüedad y civilización: entre 1932 y 1944, entre 1944 y 1953, y entre 1953 y 1962. A su vez, se propone que estos tres momentos pueden relacionarse con un cruce particular entre cuatro factores explicativos: contexto histórico, perspectivas ideológicas, formación disciplinar y posición en el campo. Se concluye constatando las maneras en que el cruce entre esos cuatro factores modela las concepciones de la historia universal, antigüedad y civilización, afirmando que es posible argumentar una relación explicativa entre lo primero y lo segundo.

\section{ABSTRACT}

The article seeks to characterize and explain the transformations Keywords: in the ideas of "universal history," "civilization," and "antiquity"

Olga Poblete,

\footnotetext{
* Chileno. Estudiante del programa de Doctorado en Estudios Latinoamericanos, Universidad de Chile. E-mail: enrique.riobo@gmail.com

Este artículo forma parte de mi tesis para el doctorado en Estudios Latinoamericanos de la Universidad de Chile Humanismo, nación y antigüedad en Juan Gómez Millas, Roberto Prudencio, Yolanda Bedregal y Olga Poblete entre 1932 y 1964. Esta tesis es también parte del proyecto FONDECYT "Discursos antipatriarcales en autoras indígenas de Guatemala, Bolivia y Chile", dirigido por Claudia Zapata.
} 
in the work of Olga Poblete between 1932 and 1962. The aim is to analyze a specific area of the Chilean author's work that has received little academic attention. We establish three different moments that mark changes in Olga Poblete's thinking about universal history, antiquity, and civilization between 1932 and 1944, between 1944 and 1953, and between 1953 and 1962. We propose that these three moments be related to a particular intersection between four explanatory factors: historical context, ideological perspectives, disciplinary training, and position in the field. It concludes by noting how the crossover between these four factors shapes conceptions of world history, antiquity, and civilization, affirming that it is possible to argue for an explanatory relationship between the former and the latter. civilization, antiquity, universal history. 
Olga Poblete es una figura conocida, y en los últimos ha sido incluso objeto de un reportaje de difusión histórica en televisión ${ }^{1}$. Usualmente es destacada en su rol como educadora, pacifista y feminista ${ }^{2}$, siendo esto último especialmente relevante por su participación en el Movimiento Pro-Emancipación de las Mujeres de Chile (MEMCH) ${ }^{3}$, y luego en el MEMCH 83. Pero todavía se conoce de forma superficial su pensamiento, especialmente el referido al ámbito historiográfico y pedagógico. Por lo mismo, este artículo busca aportar a un estudio más profundo de su quehacer intelectual, poniendo el foco en un aspecto acotado - como son las ideas sobre historia universal, antigüedad y civilización-, pero que, visto en un periodo de tres décadas, darán cuenta de interesantes transformaciones y dimensiones poco conocidas de esta historiadora y profesora.

Este trabajo se enmarca en un campo de investigación más amplio y referido al mapeo y estudio de las ideas sobre la antigüedad en América Latina ${ }^{4}$, así como también de los diversos usos del concepto de

1 Ver "Capítulo 5: Mujeres Chilenas-La Historia Secreta de Chile 2". Recuperado de https://www.youtube.com/watch?v=gNJjckpARTg, revisado el 10-I-2021.

2 Existen diversos homenajes y semblanzas que dan cuenta de esto. Uno de ellos es del Archivo Nacional, que custodia actualmente un fondo con su nombre, parte del Archivo Mujer y Género. Ver Archivo Nacional, 2021. Recuperado de https://www.archivonacional.gob.cl/616/w3-article-86872.html, revisado el 10-I-2021.

3 La historia del MEMCH ha sido estudiada con detalle recientemente. Dos ejemplos de ello son la publicación del catálogo del epistolario (Jiles y Rojas, 2017) y un reciente artículo muy completo sobre la historia del Movimiento (Jiles y Rojas, 2019). También Olga Poblete tiene un artículo que resulta revelador sobre la historia del MEMCH, pues, para ella, el problema de su final fue la tensión entre un movimiento político transversal, en contraposición a una creciente relevancia de la politización partidaria que requirió clientela femenina y se enmarcó en las polaridades de la Guerra Fría (Poblete, 1983: 166). También es importante aclarar una confusión que existe en varias semblanzas y biografías de Poblete, pues ella no fue fundadora del MEMCH, sino que entró al movimiento años más tarde.

4 La recepción de lo clásico a nivel mundial es un campo de estudios en creciente expansión. En su mayoría estos estudios se han enmarcado en Europa, Estados Unidos y el mundo poscolonial, especialmente afro (Greenwood, 2010; Hardwick y Gillespie, 2007), y se están ampliando también para América Latina, cuestión que ha mostrado un grado de especificidad importante de nuestro subcontinente (Andújar, 2020; Taboada, 2012 y 2014). En particular para el caso de Chile, existen varios estudios relevantes, aunque generalmente anclados en el marco decimonónico (Huidobro, 2018; Gazmuri, 2016; Castillo Didier, 2015; Viveros, 2020) o en el contexto colonial (Valenzuela, 2016). Existen algunos estudios sobre el siglo $\mathrm{XX}$, pero de carácter laudatorio, que buscan reafirmar una noción de legado clásico bajo el supuesto de la participación nacional en Occidente, por lo que el foco está puesto más en una lógica de tradición (Villalobos Martínez, 2016). Otras perspectivas, entre las cuales me incluyo, han puesto el énfasis en una visión más crítica sobre el asunto (Riobó y Villarroel, 2019; Sánchez y Riobó, 2020; 
"civilización" dentro del subcontinente. ${ }^{5}$ Por lo tanto, se buscará caracterizar y explicar los cambios en la enseñanza de la historia universal por parte de Olga Poblete, enfocándose especialmente en la noción de "civilización" y sus relaciones con ideas de la antigüedad. Se sugiere la existencia de al menos tres momentos diferenciados en este respecto: 1932 a 1944, 1944 a 1953 y 1953 a 1962.

El primer momento muestra una concepción evolucionista y enmarcada en la ideología de progreso, que pone en el centro al Occidente, comprendiéndolo como el eje de la historia universal. Esto último implica que, aunque se acepte la existencia de diversas culturas, el proceso civilizatorio es uno y, por lo mismo, los estadios de desarrollo (salvajismo-barbarie-civilización) y nociones raciales tienen cierto rango explicativo. Un segundo momento muestra una mirada más plural de las civilizaciones, así como también formas más reflexivas de transmisión de conocimientos. En este minuto ya no hay mención a estadios diferenciados de desarrollo, ni tampoco a nociones raciales, y se vislumbra una preocupación por lo propio en tanto América Latina. Un último momento da cuenta de una concepción que transita hacia perspectivas más anticoloniales que profundizan la concepción plural de las civilizaciones. La preocupación por lo continental es mayor, y hay una búsqueda por poner en valor lo precolombino. También se relativizan referentes históricos antes fundamentales, como el caso griego.

En un nivel explicativo, se propone que cada uno de esos momentos corresponde a un cruce particular de cuatro factores que serían fundamentales para comprender la manera en que se modelan las ideas

Sánchez, 2016). Lo anterior se complementa con estudios sobre el orientalismo latinoamericano (Taboada, 2017; Bergel, 2015), así como con la conciencia de la relación, en el subcontinente, entre las ideas de las antigüedades mediterráneas con las ideas de lo precolombino (Valenzuela, 2021). Esto último se ve reafirmado en el reciente congreso Contact, Colonialism and Comparison (2021), enmarcado en el proyecto "Antiquities in the Americas", que abordó una noción amplia de la antigüedad y los diversos cruces entre lo precolombino y lo clásico. Si hablamos de imágenes, una exposición nueva y sumamente interesante es Synthesis, de Katarina Guzmán.

5 Actualmente se desarrolla el proyecto PAPIIT-UNAM "América Latina y en enfoque civilizacional", liderado por Hernán Taboada, y dentro del cual se preparan dos publicaciones sobre el asunto. Junto con ello destaco los dossiers sobre el tema publicados en Pléyade "Civilización: genealogías e historias de una noción" (2019), y en la revista Cuadernos del CEL “América Latina como civilización” (2017). 
de "antigüedad" y "civilización": el contexto histórico, la posición en el campo, la formación disciplinar y las posturas políticas e ideológicas.

En cuanto a la estructura de este artículo, se presentará primero una breve biografía de Olga Poblete. Luego se desarrollarán con mayor detalle los factores explicativos propuestos, se presentará la revisión de la documentación que sustenta este estudio y se planteará una perspectiva metodológica. El cuerpo del artículo mostrará algunas de las formas concretas en que se expresan los diferentes momentos en su noción de "civilización" y su relación con la antigüedad.

\section{Breve reseña biográfica de Olga Poblete}

Nacida en Tacna en 1908, fue hija de madre soltera y parte de una familia obrera que llegó a Santiago algunos años después. Estudió pedagogía en Historia y Geografía en el Instituto Pedagógico durante la década del 20, egresando en 1929 y graduándose en 1942 (Méndez, 1984: 167), con una tesis que habría sido publicada en la revista Anales de la Universidad de Chile en 1953. ${ }^{6}$ De acuerdo con su propio testimonio, habiendo decidido ir a provincia a ejercer la docencia por no encontrar trabajo en Santiago al egresar, fue detenida por Eugenio Pereira Salas, incorporándose como ayudante al Instituto Pedagógico, específicamente trabajando con Luis Brieger en la cátedra de Geología (Mansilla, 2010: 104). En los primeros años de la década de 1930 fue parte del grupo Índice. Fue autora de un artículo de la revista del mismo nombre y contestó una encuesta sobre la universidad. Ingresó como profesora al Liceo Manuel de Salas en 1935, participando de la enseñanza y de la organización y creación de material pedagógico para los Estudios Sociales. Entre 1944 y 1945 viaja a Estados Unidos a hacer un máster en educación, viviendo allí el lanzamiento de la bomba atómica. En 1946 comienza a trabajar como profesora asistente en la cátedra de Historia Universal de Juan Gómez Millas. Dicha cátedra habría sido dividida

6 La revista tiene como autora consignada a Olfa Poblete Muñoz. En general, ella firmaba como Olga Poblete de Espinosa, y antes como Olga Poblete. No se ha podido encontrar otro contexto en el que firme con un segundo apellido "Muñoz", por lo cual es posible dudar de su efectiva autoría de este texto. Pero tanto la afirmación del trabajo de Luz María Méndez como la falta de antecedentes de alguien llamado "Olfa Poblete Muñoz" dentro de la Universidad de Chile, como también la relación entre el tópico estudiado con el desarrollo profesional de Olga Poblete, hacen suponer que efectivamente es su trabajo. 
entre ella, Hernán Ramírez Necochea y Mario Góngora en 1952 (Poblete, 1980: 14). ${ }^{7}$ Ella será catedrática de "Expansión Europea" y la primera profesora del Departamento de Historia de la Universidad de Chile (Méndez, 1984: 166). Durante la década siguiente también será jefa de prácticas del Instituto Pedagógico, donde llegará a ser directora durante la reforma universitaria. Con el golpe de Estado debió retirarse de la docencia y, en 1983, participó en la refundación del MEMCH, ahora vinculado con la lucha antidictatorial. A lo largo de su trayectoria académica e intelectual publicó múltiples artículos, libros y documentos, y fue pionera en el estudio de la historia de Asia y África.

En el ámbito político, Poblete fue militante del movimiento estudiantil en los años 20, comprometida con la causa republicana española y luego antifascista en la segunda mitad de los años 30, participando de la campaña de Pedro Aguirre Cerda (Mansilla, 2010: 105-106). A finales de esa década y principios de la siguiente ingresó al MEMCH, luego de haber colaborado en la exposición "La mujer en la vida nacional", organizada en el Museo Histórico y apoyada por la presidencia mediante la primera dama Juanita Aguirre de Aguirre Cerda (Poblete, 1983: 39). En 1949 fue parte del directorio del Comité Nacional Pro Paz (Poblete, 1991:27) y en 1950 la vicepresidenta del Movimiento Chileno por la Paz, presidido por Guillermo del Pedregal. Al menos desde 1946 estuvo involucrada en la militancia por la paz, pues cuenta una anécdota que, ese año, Pablo Neruda la vio en un foro sobre anti-imperialismo y decidió invitarla a comer mediante su esposa (Mansilla, 2010: 109). Su militancia activa le valió vivir varios episodios de represión, especialmente vinculados a hostigamientos y obstaculizaciones para realizar viajes hacia instancias internacionales para militantes por la paz. Uno de estos episodios es comentado en carta a Gabriela Mistral: el gobierno chileno le impidió viajar a Viena para el Consejo Mundial por la Paz y solo llegó hasta Argentina, donde fue objeto de "la más grosera intervención policial” (Poblete, 1951). Pero también pudo participar de diversos viajes vinculados a su pacifismo, siendo uno de los

7 A principios de 1953, Gómez Millas asume como ministro de Educación Pública del gobierno de Carlos Ibáñez del Campo, y más adelante, ese mismo año, se convierte en rector de la Universidad de Chile.

8 Mistral había participado del Congreso Americano por la Paz de 1949 (Albuquerque, 2011:51). 
más conocidos el que realizó a China (Ahumada, 2020: 20), y luego del cual publicó el libro Hablemos de China nueva (1953a). En 1961 ganará el premio Lenin de la Paz.

También es necesario hacer notar que Poblete fue parte del movimiento docente de la década de 1950 especialmente, publicando múltiples artículos en la revista Educadores del mundo y participando de diversos congresos internacionales para profesores. En el VI Congreso Americano para Educadores, de 1957, Poblete realiza un homenaje a Gabriela Mistral. En 1960 participó de la Tercera Conferencia Mundial de Educadores y luego fue invitada a Moscú, donde presenció el proceso al militar estadounidense Francis Gary Powers. Ella fue cercana al Partido Comunista, y participó también de la Unidad Popular, especialmente en la conferencia de la UNCTAD III. Durante esos años publicó una serie de documentos para el estudio de la historia universal con la editorial Quimantú. Posteriormente, participó activamente de la resistencia a la dictadura. Algunas de sus memorias y reflexiones más tardías están consignadas en entrevistas que pueden verse en Youtube. ${ }^{9}$ Muere en 1999.

\section{Factores explicativos, corpus y metodología}

La propuesta principal de este artículo es que se puede establecer una relación entre los cambios en las ideas de "historia universal", "antigüedad" y "civilización", con las transformaciones en cuatro ámbitos de la vida de Olga Poblete, a saber: el contexto histórico, sus perspectivas políticas, su formación disciplinar y su posición en el campo. En los siguientes párrafos se dará cuenta de las mismas en relación con la vida de Olga Poblete durante el periodo a trabajar.

Contexto histórico: Hace referencia a dos dimensiones. La primera es la mundial, marco en el que interesa relevar la importancia de la II Guerra Mundial como una suerte de antes y después para la posibilidad de usar un discurso racial tan explícito como antes de mediados de la década del cuarenta. Otro proceso relevante, previo a 1944, es la guerra civil

9 “Material de Cámara. Entrevista a Olga Poblete y Elena Caffarena 2a parte. 1989. Diamela Eltit". Recuperado de https://www.youtube.com/watch?v=OykVsebxgSc\&t=2s, y “Material de Cámara. Entrevista a Olga Poblete y Elena Caffarena $3^{a}$ parte. 1989. Diamela Eltit". Recuperado de https://www.youtube.com/watch?v=nfTUppZvQ1k\&t=813s. 
española, especialmente porque Poblete se abanderó con los republicanos españoles. Con posterioridad a 1945 se abre otro conflicto geopolítico, como fue la Guerra Fría entre los Estados Unidos y la Unión Soviética. Una dimensión del mismo fue la llamada "Guerra Fría cultural", en la que la disputa conceptual tuvo en la palabra "paz" una fuente de conflictividad (Mistral, 1950) y especial cercanía con el mundo comunista (Albuquerque, 2011). En ese marco comienza también a desarrollarse un proceso de descolonización, especialmente presente en Asia y África.

Una segunda dimensión de contexto es la nacional. Entre 1932 y 1944 se venía saliendo de la dictadura de Ibáñez y de una grave crisis institucional y política. Por lo mismo, nuevas fuerzas políticas y sociales aparecen o se fortalecen, especialmente por el sentimiento antiliberal derivado de la crisis oligárquica en general, y la crisis del 29 en particular. Entre los partidos existe una relativa estabilidad, matizada con varios intentos de golpe, uno de los cuales termina con la matanza del Seguro Obrero, lo que abre la puerta para que el Frente Popular llegue al gobierno en 1938. Esta coalición iba desde el Partido Radical hasta el Partido Comunista. Los gobiernos radicales estarán en el poder hasta 1952 pero, tanto por desavenencias políticas internas como por el contexto internacional, durante el gobierno de Gabriel González Videla se desarrolla un quiebre con el Partido Comunista, que será declarado ilegal mediante la ley de defensa permanente de la democracia, en 1949. Esto provocó quiebres también en varios partidos y movimientos, incluido el MEMCH. El PC volvió a la legalidad a finales del segundo gobierno de Ibáñez del Campo. A inicios de la década de 1960, este partido desarrollará una política específica hacia la Universidad de Chile, lo que tuvo repercusión en las discusiones universitarias sobre el proceso de reforma a finales de esa década, en el que Olga Poblete y Hernán Ramírez Necochea tuvieron figuración importante, especialmente en la Facultad de Filosofía y Educación (Villar, 2020). Junto con lo anterior, especialmente desde la creación de la CORFO, se desarrolla una política industrial y desarrollista que tendrá un crecimiento, un auge y una crisis creciente desde finales de la década de 1950 e inicios de la siguiente. Hacia finales del periodo estudiado comienza a desarrollarse un proceso de creciente politización popular y fortalecimiento de las posiciones de izquierda, cuestión que tiene como un factor relevante a considerar las consecuencias continentales de la Revolución Cubana, que envalentonaron tanto a las fuerzas que 
buscaban transformaciones profundas como a las más conservadoras que resistían cualquier cambio.

Perspectivas politicas: Se refiere a las principales posturas políticas que pueden encontrarse en el pensamiento de determinada figura. Estas no se manifiestan exclusivamente en militancias formales, sino que trasuntan hacia las posiciones o intereses que se busca defender en uno u otro momento. En el caso de Olga Poblete, las posiciones democráticas y de izquierda fueron transversales en su vida, aunque en los años 30 parecen entremezcladas con un nacionalismo que irá decayendo con el tiempo. Por otro lado, el ingreso al MEMCH implicó una incorporación de perspectivas feministas y de género a su acción. Con posterioridad, se hará una militante por la paz, desde donde se vinculará con su labor educativa, y tejerá lazos importantes con militantes comunistas, como Hernán Ramírez o Alejandro Lipschutz.

Los hitos temporales de 1944 y 1953 tienen cierta relevancia en este proceso. En primera instancia, por el lanzamiento de las bombas atómicas, que Poblete vivió en Estados Unidos, lo que marca una sensibilidad con las luchas por la paz. Por otro lado, a principios de la década del cincuenta Poblete adquiere una visibilidad mayor. Participa en el Segundo Congreso Mundial de Partidarios de la Paz, en Varsovia, durante 1951, a lo que se refiere en el documento "La paz no se espera, se conquista", que también versa sobre la situación coreana del minuto. Además se publica Hablemos de China nueva, en 1953, a propósito de la participación de Poblete en la delegación chilena que asistió al Congreso de los Pueblos de Asia y del Pacífico, realizado en Pekín en 1952. Su militancia por la paz tenía un vínculo relevante con el Partido Comunista, cuestión que se puede apreciar en la cobertura que tenía Olga Poblete dentro de un medio como El Siglo, en el que hay varias reseñas a su labor, discursos y posturas. A finales del periodo estudiado, en 1961, ganará además el premio Lenin de la Paz, lo cual también da cuenta del carácter de sus perspectivas políticas.

En ese marco, su pensamiento fue adquiriendo un carácter antirracista, anticolonial y antiimperialista. En particular, resulta interesante hacer notar el rol que Alejandro Lipschutz parece haber tenido en la afirmación de estas posturas, como lo consigna la misma Poblete (1990). Esto es importante, porque el científico lituano era un pensador especialmente comprometido con la lucha contra el racismo y la 
exclusión de los pueblos originarios, y escribió significativos aportes en ese sentido.

Formación disciplinar: Se refiere a los procesos formativos de la figura en cuestión, con énfasis en la disciplina cultivada, en las escuelas de pensamiento principales con que se relaciona académicamente, y con los espacios institucionales en que se desarrollan sus estudios. En el caso de Olga Poblete, dos elementos deben destacarse. El primero se relaciona con que Poblete fue formada en un contexto en el que ya se estaba desarrollando un proceso de profesionalización de la historia como disciplina específica, aunque en su formación de grado aún no existía una institucionalidad vinculada a la investigación histórica autónoma, cuestión que se irá desarrollando especialmente durante mediados del siglo XX. Esta situación implica un lugar pionero del trabajo de Poblete en la modernización de la enseñanza de la historia, por ejemplo, otorgando centralidad a lo geográfico o al uso de documentación. Esto último, a su vez, es coincidente con el estudio de un máster en Columbia, Estados Unidos, a mediados de la década de 1940. Junto con lo anterior, y especialmente desde la década de 1950, su exposición a otros sistemas educativos del orbe también fue significativa en su formación. De hecho, hay reflexiones sobre la educación china o vietnamita que aparecen como referentes en su pensamiento educativo. A lo anterior se debe sumar su labor como dirigente del magisterio, marco en el que la experiencia internacional adquiere relevancia para pensar la enseñanza en Chile. Todo esto va enriqueciendo su mirada a la disciplina histórica, así como a su lugar político y social.

Un segundo elemento se vincula con ciertas escuelas de pensamiento a las que Poblete estuvo expuesta. En los años treinta, el culturalismo alemán era parte sustancial de la discusión historiográfica, siendo especialmente relevante la figura de Oswald Spengler y su aplicación del método analógico. ${ }^{10}$ Esto es fundamental, porque introduce una crítica a la concepción de la civilización como torrente universal de progreso, aun-

10 Este método supone que el desarrollo de cada cultura/civilización tiene etapas más o menos análogas, aunque con un carácter histórico irreductiblemente particular. En ese sentido, se plantea que es posible conocer el estado de desarrollo de las culturas/ civilizaciones para comparar diversos ámbitos de cada una de ellas. En el caso de Olga Poblete, esta metodología se aplica de forma clara en su artículo publicado en la revista Índice "En busca de un hombre" (1931). 
que esta última todavía está presente. Además de ello la relevancia de lo geográfico como factor explicativo del desarrollo cultural humano. Esto dialogaba tanto con la antropogeografía, basada especialmente en ideas de Friederich Ratzel y enseñada en la época por Luis Galdames (1955), como en autores vinculados a una primera escuela de los Annales, como Lucién Febvre. Estas posiciones parecen haber sido importantes, especialmente en el periodo previo a su máster en Estados Unidos. Una vez de regreso de dicho viaje, se incorporan ideas más ancladas en una concepción más plural de las civilizaciones, cuestión que iba de la mano con las ideas de Toynbee, muy significativas en Estados Unidos durante la época (Grossi, 2017: 2010). Además, hay una preocupación mayor por la dimensión pedagógica de su trabajo y el rol social de la enseñanza de la historia. Junto con ello, las posiciones más culturalistas comienzan a diluirse para dar paso a una reflexión menos mistificante y más anclada en documentación concreta. En ese sentido, es posible pensar en que reflexiones vinculadas a la Escuela de los Annales ${ }^{11}$ crecen en relevancia, especialmente porque se fueron incorporando al curriculum chileno de los sesenta, que tenía a Poblete como una autora recomendada (Aguayo, 2017: 14). También es posible pensar que su rol como militante por la paz implicó la incorporación de perspectivas históricas ancladas en una concepción antiimperialista, especialmente porque es posible vislumbrar formas concretas en que se eleva el estatuto histórico de civilizaciones y pueblos que previamente eran invisibles, o considerados como inferiores o atrasados.

La posición en el campo: Utilizando el concepto campo de Bourdieu (1997), hacemos referencia a dos sistemas de posiciones interconectados. Por un lado, el ámbito institucional y académico, en el que las figuras fueron ocupando posiciones diversas a lo largo del tiempo, pasando a veces de ser dominantes a marginales o viceversa. El criterio para definir aquello es más institucional, y hace referencia a las posiciones de poder dentro de las universidades u otros ámbitos académico-intelectuales. A su vez, la revisión de este campo implica también una mirada a las distintas estrategias de posicionamiento dentro del mismo, las cuales serán diversas dependiendo de ciertos factores de inclusión/exclusión exter-

11 De hecho, tengo referencias de una carta de Olga Poblete a Fernand Braudel, aunque me ha sido imposible conocer su contenido hasta ahora, pues se encuentra en Francia. 
nos a lo meramente académico, a saber, redes políticas y de contactos, condición social, género, color de piel o distancia con las hegemonías disciplinares. Por cierto, lo anterior se encuentra plenamente vinculado al ámbito de lo político y cultural, donde las figuras actúan de distintos modos; y si bien allí también operan factores de inclusión/exclusión diversos, las posiciones no siempre están alineadas con las académicointelectuales. Por ejemplo, Olga Poblete ocupaba una posición central en el movimiento feminista primero, y luego en el movimiento chileno de partidarios de la paz, pero ello no tiene un correlato con su posición académico-institucional que, por lo menos hasta 1952, era secundaria e intermedia entre la universidad y el liceo. Pero durante la década del cincuenta, y especialmente en los sesenta, su notoriedad académica se hace mayor y va ocupando lugares más centrales y dominantes, cuestión que va de la mano con una creciente fuerza de la izquierda en la Universidad de Chile, y en el país en general.

Una segunda dimensión son las estrategias de posicionamiento (Stecher y Cisterna, 2020) que se han identificado, algunas de ellas típicamente femeninas de la época. Por ejemplo, la necesidad de ser "validada" por figuras masculinas dominantes, como Juan Gómez Millas o Eugenio Pereira Salas. Esta es una cuestión que aparece al menos hasta 1953. Más adelante será incluso ella prologuista de otros importantes autores, como el caso de Hernán Ramírez Necochea. Por otro lado, otra estrategia de posicionamiento, como es la necesidad de mostrarse poco amenazadora y conflictiva en su trabajo intelectual académico, implicó levantar una barrera con su compromiso político, la que es especialmente clara en el caso de su militancia femininsta, pero que fue decreciendo a medida que su posición estaba más consolidada, ya más entrada la década del cincuenta.

Otra estrategia de posicionamiento fue la participación en el llamado Invisible College (Pizarro, 2004), que implicaba una red de vínculos con otras intelectuales mujeres, en la que Gabriela Mistral jugó un rol significativo, especialmente a inicios de la década del cincuenta, por la complicidad derivada de la militancia por la paz.

\section{Corpus}

Para realizar esta investigación se revisaron las revistas Índice, Clío, Boletín del Liceo Manuel de Salas, Educadores del Mundo y Anales de la 
Universidad de Chile. Junto con ello se revisaron las guías de estudio que Olga Poblete realizó para el Liceo Manuel de Salas, las compilaciones de documentos para el estudio de la antigüedad y la historia universal, y los libros publicados por la autora en el periodo (principalmente sobre China). También se revisaron diversos episodios en el periódico El Siglo. Estos materiales se encuentran en la Biblioteca Nacional, en la Biblioteca de la Facultad de Filosofía y Humanidades de la Universidad de Chile, y en colecciones digitales de la Biblioteca del Congreso Nacional y de la Universidad de Chile.

\section{Perspectiva metodológica}

La metodología está basada en el trabajo heurístico y hermenéutico con el corpus seleccionado. En particular, se seleccionaron aquellos pasajes e ideas que tuvieran relación con la noción de "antigüedad" y, a partir de allí, se construyeron las relaciones con las ideas de "civilización" e "historia universal". También se consideró con un lugar relevante a las referencias a lo griego y a lo precolombino, principalmente porque sus transformaciones son claras y dan cuenta palmaria del proceso que se busca graficar. Por otro lado, dada la poca investigación profunda sobre el pensamiento de Olga Poblete, estas indagaciones tienen un carácter exploratorio que puede y debe ser enriquecido.

\section{Historia universal, civilización y antigüedad en Olga Poblete}

Una de las transformaciones más interesantes que pueden constatarse en el pensamiento de Olga Poblete durante el periodo estudiado es el paso de una concepción civilizatoria - en la que las etapas de salvajismo, barbarie y civilización son esenciales y se superponen incluso a una lógica cronológica - hacia una más temporal y plural. Esta última enfatizará crecientemente en un descentramiento del eje europeo de la "historia universal" ${ }^{12}$, poniendo en valor la historia y cultura de civilizaciones colonizadas. Junto con ello, también se constata una trans-

12 Uso entre comillas el término historia universal porque me importante hacer notar que se está haciendo referencia a un uso de la época, más que a una constatación del carácter universal de la historia europea. Sobre este tópico, hay bastante reflexión crítica que muestra la naturaleza eurocéntrica e incluso racista de tales concepciones (Chakrabarty, 2001). 
formación en los métodos de enseñanza de la historia, que era una de las centralidades de su trabajo como catedrática de la Universidad de Chile. Uno de los cambios fundamentales radica en el paso de una lógica más descriptiva y memorística hacia una más vinculada al análisis y reflexión sobre la base de documentación. En cualquier caso, el nivel de especificidad que tienen estas labores es una cuestión sumamente interesante, y que muestra que el estatuto de la "historia universal" ha sido muy importante dentro de la enseñanza de la historia en Chile.

En ese marco, uno de los elementos más significativos que podemos hacer notar es cómo cambia el lugar que se le asigna a la antigüedad americana dentro de la historia. Es que en sus trabajos más tempranos lo precolombino ocupa un lugar inicial, casi primitivo y comparado con el hombre prehistórico, que se presenta como previo a otras culturas y pueblos cronológicamente posteriores. Pero en trabajos posteriores, y más aún en periodos posteriores a este estudio, la comparación entre precolombinos y prehistóricos desaparece, y estos pueblos dejan de incorporarse a periodos de salvajismo o barbarie para ser incluidos en la historia moderna como un grupo más de pueblos o culturas, que conviven con las europeas de la época.

Un elemento que parece importante en esta transformación es la creciente conciencia de las problemáticas colonialistas e imperialistas que estaban en la base de la militancia por la paz, y que se vinculaban también con el pensamiento racista.

\section{2-1944: Civilización como torrente de progreso y el Occidente como su medida}

En este marco es interesante constatar que en los primeros trabajos de la profesora sí existen ciertos elementos de discurso racial como dispositivos de explicación histórica ${ }^{13}$, muchas veces entroncado con una lógica civilizatoria que termina subordinando a una concepción más plural de las civilizaciones del mundo, incluso si es que el referente estudiado es ajeno a Europa. Debemos considerar que, hacia las décadas de 1930 y 1940, también se desplegaba una crítica a la lógica

13 Referido a elementos como migraciones y mezclas étnicas; razas concebidas como diferenciadores culturales que pueden o no estar vinculados a jerarquías sociales o datos antropométricos. 
civilizatoria desde miradas más historicistas, de las cuales Spengler será uno de los adalides. Pero, en el caso chileno, no parece alcanzarse una oposición plena entre sendas propuestas, sino que más bien tienden a conciliarse, incorporando, por ejemplo, dimensiones culturalistas de carácter místico-histórico, como la búsqueda de los símbolos primarios o el problema del origen, con una concepción de la historia como torrente universal. Por cierto, Olga Poblete parecía en algún grado consciente de ello y, desde sus inicios, pueden verse intentos por superar tales concepciones. Lo anterior se ve de forma muy clara en su artículo sobre la historia antigua de India, China y Japón, publicado en dos partes por los números 1 y 2 de Clío, y correspondiente a un resumen de un curso sobre Historia Antigua del Extremo Oriente, de 1933. Allí se dialoga con unas perspectivas antropológicas que conciben la evolución humana como un proceso único, aunque con temporalidades muy diversas y clasificadas en tres grandes grupos, con diversas gradaciones: salvajismo, primitivismo y civilización. ${ }^{14}$ A su vez, esto se entiende como anclado en unos espacios geográficos ${ }^{15}$ concretos, que permiten delimitar ciertas zonas históricas "en las que los estímulos del medio y las reacciones del hombre sometido a éste, han concurrido a producir un desarrollo cultural, perfectamente individualizado" (Poblete, 1933a: 19). De ahí que sea imposible referirse de forma homogénea a un espacio tan vasto como Asia.

En un primer momento, se distingue entre dos zonas fundamentales: la central-occidental y la oriental-meridional. Desde la primera se habrían dado grandes invasiones o migraciones hacia la segunda, por lo que se considera una relación centro-periferia, en la cual las civilizaciones de India, China y Japón serían parte de la segunda zona y, por ende, subsidiarias de la primera en cuanto a su desenvolvimiento evolutivo. Por lo mismo, Poblete manifiesta que las últimas investigaciones sobre el Extremo Oriente contradicen las posiciones de Eduar-

14 Estos conceptos vienen de la antropología y la arqueología evolucionistas, y fueron creados por Lewis Henry Morgan. En una línea similar se encuentra John Lubbock, quien crea conceptos - como paleolítico o neolítico-, referidos especialmente a la prehistoria.

15 Cabe hacer notar que esta relación entre antropología y geografía se encontraba en la cátedra de antropogeografía que desarrollaba Luis Galdames, y se basaba especialmente en la obra de Friedrich Ratzel. El programa de este curso se encuentra en Galdames, 1955. 
do Meyer en el tomo I de Historia de la antigüedad, en las cuales se propone que, al igual que en Egipto y en Babilonia, en China aparece una civilización superior de forma autónoma.

En cuanto al estudio de la prehistoria de la zona, se afirma que aún la investigación está en ciernes, porque el "Extremo Oriente ha sido tardíamente incorporado a la corriente de la historia universal" (Poblete, 1933a: 20). Dentro de este terreno especulativo, problemáticas vinculadas a las migraciones arias y a contactos entre pueblos antiguos aparecen como centrales, y se vinculan con la necesidad de clasificar las etapas de desarrollo cultural. En ese sentido, aparecen referencias a culturas del mediterráneo antiguo como formas para dilucidar el estado de avance en cada caso. Por ejemplo, en cerámicas, China se asimila al "sub-neolítico cretense y el tesaliano antiguo" y, a renglón seguido, se compara a la India con "las piezas análogas de Suza y trae reminiscencias de la cerámica del área Egea” (21). En el caso de la India, se entrega un valor central a las múltiples migraciones que han producido allí un mosaico étnico importante. En torno a los estudios antropológicos, Poblete manifiesta interés, porque "un análisis de los caracteres cránicos ha llevado a afirmar que la India entera es dolicocéfala, conclusión en extremo curiosa, si se toma en cuenta que precisamente en todas las regiones vecinas a la India, domina una marcada braquicefalia" (23). Este dilema la lleva a referirse a las diferencias entre las poblaciones pre-arias y los arios. En esta explicación, las lenguas y los pueblos aparecen como indistintos, pues se distinguen entre los prearios dos lenguas (mundas y drávidas), que corresponderían a la población autóctona de la India y a invasores emparentados con los sumerios, respectivamente. Luego vendría el dominio de los conquistadores arios, quienes llegarían en grandes oleadas migratorias pacíficas y de familias completas desde "la región alojada entre los Cárpatos por el este, los Balkanes por el sur, los Alpes austriacos, Böhmer Wald, por el oeste y los Erzgebirge por el norte" (24).

De este modo, lo sucedido en el pasado se proyecta hacia el presente, como elemento explicativo de las características craneales de los indios actuales. En el caso chino ocurre algo similar, aunque en el sentido inverso pues, dadas las mezclas étnicas, la raza sería indistinguible en los primitivos habitantes (Poblete, 1933b: 9). Además, se 
afirma que China actuó como una suerte de Roma para otros pueblos de la zona, en la medida que les llevó la civilización, cuestión que sería el caso de Japón (13). Estas reflexiones se encuentran soportadas por una bibliografía actualizada para el contexto, la mayoría en francés y editada en París. Varios de estos libros siguen disponibles en la biblioteca de la Facultad de Filosofía y Humanidades (FFyH) de la Universidad de $\mathrm{Chile}^{16}$, por lo que es posible suponer que se accedió a ellos mediante la universidad. En ese sentido, la dimensión especulativa del artículo es menor, y el afán de mostrar una actualización en la investigación historiográfica mundial es claro. En ese contexto, estar al día implicaba utilizar nociones de carácter racial y antropométrico, y preocuparse por migraciones ancestrales. De hecho, décadas más adelante ella opondrá la actitud especulativa a una más científica, al referirse al momento en que ejercía como ayudante de la cátedra de historia universal de Juan Gómez Millas (Mansilla, 2010: 103 y 107).

Unos años más tarde, en 1935, Poblete comenzó a trabajar en el Liceo Experimental Manuel de Salas (LMS), donde se desempeñó como profesora de Estudios Sociales. En ese contexto desarrolló diversas iniciativas que, por el carácter experimental y vinculado al IP de la Universidad de Chile del LMS, pueden considerarse como modernizadoras. Por ejemplo, elaboró encuestas referidas a los intereses vocacionales de los alumnos y usos del tiempo libre, que pueden vincularse con los inicios de la Orientación en Chile, en la medida que el LMS era un preludio de las políticas aplicadas en otros liceos (Toro, 2018: 301). También es partícipe de procesos de organización de los alumnos, entre los cuales se destaca la organización del Centro de Estudios Sociales, en el que se interpretó "un trozo de una tragedia griega como ensayo de reconstitución de época", y que fue un antecedente de los Centros de Estudios del LMS (Glavic, 1944: 49-54; Poblete: 1944a: 55-58). Pero lo más significativo para este caso fue la confección de guías de estu-

16 El detalle es: Cahun, L. Introduction a l'historie de l'Asie, París, 1896; Deniker, J. Les Races et les Peuples de la Terre, París, 1926; De Morgan, J. L' Humanité Prehistorique, París; Pittard, E. Les Races et L'Histoire, París; Grousset, R. Histoire de l'extreme Orient, 2 vols., París, 1929; Masperó, H. La Chine Antique, París, 1929; The Cambridge Indian History, Cambridge, 6 vols., 1928; La Vallée Poussin, M. L'Inde jusque vers 300 avant J. C., París, 1926. Solo el libro de Cahun y los volúmenes 2, 4 y 6 de la historia de Cambridge no están en la Biblioteca actual de la FFyH. 
dio para la enseñanza de la Historia y Geografía, las que se publicaron como cuadernillos por la imprenta de la Universidad de Chile en diversas ocasiones. El primero de estos materiales es el que más interesa, pues refiere al cuarto año de humanidades y tiene como objeto de estudio la civilización y la antigüedad. El documento está estructurado en guías que, a su vez, se subdividen en varias partes: "Introducción a la materia. Instrucciones para el trabajo. Bibliografía. Desarrollo de la Guía. Ejercitación. Trabajos complementarios" (Poblete, 1944b: 7). Dentro de este documento se trabajan los pueblos precolombinos y, de manera mucho más dilatada, la Grecia antigua. Es considerado por Florencia Barrios, rectora de la institución, en su prólogo a la guía de Poblete, como una primicia que busca divulgar la nueva metodología que implementa el LMS (1944b).

En estas guías todavía pueden identificarse ciertos elementos de los discursos raciales que están operando como dispositivos explicativos de la historia de estos pueblos, pero tienen una relevancia menor, especialmente si se comparan con otros instrumentos de la época, en los que se planteaban, de forma explícita, nociones racistas y supremacistas blancas, e incluso se relevaba hasta la majadería el salvajismo e inferioridad de los precolombinos, a propósito de cuestiones como el canibalismo, la falta de animales, la inexistencia de la verdadera cultura (se llegó a negar que tuvieran agricultura). Pero, igualmente, la jerarquización de grupos humanos es explícita y, en ella, el concepto de "civilización" aparece como central. En efecto, la guía de estudio $\mathrm{N}^{\circ} 1$ se denomina "Los orígenes de la humanidad y las primeras formas de vida social. La humanidad prehistórica" comienza de la siguiente manera:

"Vivimos en un mundo civilizado. Esto lo sabemos y se repite a diario.

$¿$ Ha pensado Ud. Antes en el significado de esta palabra 'civilización', en forma profunda, de modo que alrededor de ella se hayan suscitado una serie de reflexiones? Cuando decimos 'civilizado', pensamos inmediatamente en el progreso, en los perfeccionamientos técnicos que nos han permitido rodearnos de comodidades y que han facilitado nuestros trabajos, y en general nuestra existencia entera; en los progresos del espíritu y todas las creaciones maravillosas de que él es capaz, así como en la extensión de la cultura, del saber y de todos los conocimientos" (9). 
A renglón seguido, entiende que el ramo de historia tendrá por tarea dar a conocer el progreso y desarrollo humanos, los que se conciben como ascendentes, aunque con temporalidades y características distintas. En ese sentido, la civilización adquiere un segundo sentido - complementario de la civilización concebida como progresoque se vincula a la especificidad de los diversos pueblos del orbe. Esto, a su vez, se relaciona íntimamente con los medios naturales en que los grupos humanos viven y de los cuales dependen, llegando a afirmar que hay civilizaciones "tan variadas casi como los paisajes que ofrece la tierra" (11). El inicio de la civilización como progreso se proyecta hacia los alrededores del Mediterráneo europeo, donde habría nacido la agricultura y el sedentarismo, considerados como condición necesaria para la vida social y política. En este momento aparece una posible referencia culturalista: "Al mismo tiempo la permanencia continuada en un mismo lugar, dejó al individuo espacio suficiente para que su espíritu creador descubriese y perfeccionara formas, cada vez más refinadas" (Ibíd.). La relación que se establece entre cultura y paisaje es reminiscente de la noción spengleriana de símbolo primario. Pero no hay mayor desarrollo del tema. Entre estas primeras civilizaciones - que se conciben todavía como prehistóricas- se mencionan Egipto, Mesopotamia, India y China. Luego se incorporan las culturas precolombinas a la lista y se detallan las siguientes, que se adscriben a unos medios físicos muy favorables, como son las zonas tropicales: "Maya, Azteca, Nazca, Chimú, de Tiahuanaco, e Incásica” (Ibíd.). La mención a las culturas precolombinas es escueta en la presentación de esta primera guía, que termina con una recomendación para consultas bibliográficas. ${ }^{17}$ Su lugar dentro del esquema de materias también es reducido. Una de siete se refiere a las culturas americanas en general y a su "alto grado de desarrollo, antes de la llegada de los europeos" y la última es específica sobre Chile: "Las culturas prehistóricas chilenas dependen de otras, como la cultura Atacameña y la de Tiahuanaco, ambas anteriores a

17 Las copio de forma literal: Capítulo Prehistoria en cualquier manual de Historia de la Antigüedad.- M. Hoerness: Prehistoria, Colecc. Labor.- L. Fébvre. La tierra y la evolución humana.- H. Van Loon, Historia de la Humanidad.- Zorrilla San Martín, Historia de América Cap. I a IV.- C. Pereyra, Breve historia de América, Cap. 'Los aborígenes. En esta recomendación bibliográfica aparece mencionado Lucién Febvre, lo que indica un acercamiento hacia una primera Escuela de los Annales. 
la Incásica" (12). Las otras materias se remontan mucho más atrás, y dicen relación con los primeros restos humanos (Neanderthal, Java y Pekin) y con las etapas del progreso humano, el perfeccionamiento técnico y las diferencias entre salvajismo y barbarie. También se recomienda como actividad preliminar una visita a la sección "Prehistoria" del Museo Histórico Nacional. Hacia el final de esta guía se sugieren lecturas complementarias, enfocadas especialmente a los pueblos andinos y a los mapuche. ${ }^{18}$

En suma, lo indígena se enseña en esta guía desde una perspectiva evolucionista, que entendió a los pueblos indígenas contemporáneos como una suerte de "fósiles vivientes", y que niega un estatuto histórico a los pueblos precolombinos, emparentándolos mucho más con el mundo prehistórico que con la modernidad europea, aun cuando, cronológicamente, esa sería una correspondencia adecuada. Tampoco se proyecta ningún tipo de relación o flujo histórico entre ese pasado y la contemporaneidad de la época, lo que indica una perspectiva nacionalista y mestizófila, que supone la necesidad de que los pueblos indígenas de ese momento se actualizaran e incorporaran a la nación moderna (Zapata, 2013: 108-121).

Entre la segunda y la cuarta guía se comienza a desarrollar lo que se denomina como "historia antigua de Oriente". Los títulos de las guías son "Las sociedades humanas más antiguas. Las culturas de los valles fértiles: Egipto, Mesopotamia, India”; "Religión y arte en los

18 Se proponen los siguientes textos: Ernesto W. de Moeschach: Vida y costumbres de los araucanos (p. 231-330-350-395); Tomás Guevara: Chile Prehispano, Tomo I, Cap. I, VII y VIII. Tomo II, Cap. XV y XXIII; Ricardo Latcham: Prehistoria chilena Cap. I, III, V, VII, IX y XI; Ricardo Latcham: Arqueología de la región atacameña. Cap. II, X y XI; Ricardo Latcham: La alfarería indígena chilena. pp. 47 y ss.: Los procedimientos de la alfarería. p. 27: Cronología cultural para el norte de Chile. p. 60. La cultura diaguita chilena. Ricardo Latcham fue un arqueólogo inglés que se especializó en el estudio de las culturas precolombinas chilenas, poniendo énfasis en las distinciones entre los diversos pueblos que habitaron el territorio actualmente chileno. Aceptaba la cualidad civilizada de al menos algunos de esos pueblos. Desarrolla una teoría para el origen de los araucanos que se enmarca en lo que Cristóbal Gnecco ha denominado "catastrofismo" (2002 y 2009). Tomás Guevara fue un etnógrafo dedicado al estudio del pueblo mapuche, publicando textos del tema especialmente en los Anales de la Universidad de Chile en la década de 1910. Trabajó con Manuel Manquilef, consignado como informante, denotando una relación de subordinación que invisibilizaba la condición intelectual de este último (Zapata, 2015: 91). Esto es hoy criticado; de hecho, la actual reivindicación del lugar de Manquilef como coautor de los estudios de Guevara ha sido un gesto anticolonial desde el presente (Antileo, 2020: 80). 
pueblos de Oriente antiguo"; "El pueblo israelita y su gran rol religioso en la historia de la humanidad". La quinta guía del cuadernillo se denomina "Las civilizaciones marítimas del mediterráneo antiguo: cretenses, aqueos, jonios y fenicios", y aspira a mostrar la entrada en la Historia de los primeros pueblos del mar. Resulta claro, entonces, que un subtexto en la ordenación de estas materias sería que, en algo así como el proceso civilizatorio humano, los pueblos precolombinos se encontraban más atrás que los pueblos del antiguo mediterráneo. La participación en la Historia resulta una cuestión fundamental para establecer esta jerarquía, y ello implica que los criterios para definir tal inclusión están siendo eurocéntricos. En este sentido, los conceptos de "historia" y de "civilización" adquieren matices diferentes, pues el segundo parece remitir a un cierto estadio de desarrollo material, que sí tuvieron algunos pueblos precolombinos; mientras que el primero apunta a una inclusión en una cierta centralidad geopolítica mundial (la corriente principal), de la que los precolombinos habrían carecido absolutamente. En ese marco, estas civilizaciones marítimas juegan el rol de "teloneros" para la entrada del Occidente al escenario, mediante los griegos. En la introducción a la guía se enfatiza la especificidad de las actividades marítimas como distintivas de su acción. La colonización que llevan a cabo se significa desde un lugar claramente teleológico: "van produciendo un internacionalismo en el mundo Mediterráneo, el que culminará en la época romana del 'Mare Nostrum"' (Poblete, 1944b: 50). Hay menciones a las ruinas de Creta y los estudios de Evans sobre el tema.

Durante esta unidad, el trabajo geográfico resulta fundamental, y se empieza a introducir el Mediterráneo oriental y su relación con el desarrollo de los pueblos que allí convivieron. Esto se hace de modo detallado y mediante una seguidilla de ejercicios similares que se despliegan a lo largo de tres guías, para cuya resolución se entregan los siguientes títulos bibliográficos: G. Glotz, La civilización Egea; V. Jarsé, La formación del pueblo griego; L. Robin, El pensamiento griego y los orígenes del pensamiento científico. Homero, La Ilíada y La Odisea. (Poblete, 1944b: 51). Entre estos ejercicios hay uno que solicita caracterizar a los pueblos cretenses, aqueos, jonios y fenicios haciendo un cuadro resumen que incluya "Raza a que pertenecen .- Región que ocuparon .- Actividad característica .- Ciudades más importantes" (Poblete, 1944b: 55). La raza aparece como un factor más para la com- 
prensión histórica de estos pueblos, pero no parece ser preponderante a nivel explicativo.

La guía siguiente se denomina "El mundo occidental. La ciudad estado griega y el nacimiento del espíritu científico", y comienza con la oposición entre indoeuropeos y semitas, la que se proyecta hacia el presente:

"Ya en la Guía anterior estudió Ud. el aparecimiento de los Indoeuropeos en la zona del Mediterráneo: Aqueos y Dorios. Vamos a dejar, pues, el mundo oriental y las razas semíticas y camitas, para empezar el estudio de pueblos que se han ligado íntimamente a nosotros, por la sencilla razón de que hoy mismo nos encontramos viviendo, sintiendo y pensando, casi con los mismos elementos fundamentales que ellos elaboraron. Se ha dicho de los griegos, y con razón, que fueron los grandes maestros del mundo antiguo, pero también lo siguieron siendo. Todavía para las generaciones que vinieron después, y a través de ellas se ha prolongado su influencia hasta nuestros días" (Poblete, 1944b: 57).

Esa condición de maestros se justifica especialmente porque con ellos habría aparecido por primera vez "el valor de la personalidad humana en sí misma" (Poblete, 1944b: 57), cuestión que implica una valoración de la individualidad por sobre la mera masa, lo que diferencia de forma cualitativa a los griegos de los pueblos anteriormente revisados, cuyas sociedades habrían estado divididas esencialmente entre un jefe supremo y la masa de súbditos. ${ }^{19}$ Esto redundaría en que estaban sumergidos en el misterio y la religiosidad, de las que los griegos comenzaron a salir para avanzar en todo ámbito, cuestión que supone el llamado "milagro griego" (Poblete, 1944b: 57-58).

Al igual que en las guías anteriores, luego de sugerir obras de consulta $^{20}$, se organizan los contenidos en partes y problemas. Se distinguen dos: "La historia del pueblo griego. Etapas de su evolución política, social y económica” y “La cultura griega. Las creaciones más

19 Para una crítica a estas concepciones, recomiendo especialmente Vlassopoulos, 2007.

20 La formación del pueblo griego, de V. Jardé; Mitología griega y romana, de H. Steuding; El arte en Grecia, de Ridder y Deona; La ciudad griega, de G. Glotz; La ciudad antigua, de Fustel de Coulanges; Historia de Grecia, de H. Swoboda. 
importantes en el arte, la religión, el pensamiento filosófico y científico" (Poblete, 1944b: 59). De los problemas se desprende que el periodo estudiado va desde la aparición de las polis hasta el imperialismo ateniense y la Guerra del Peloponeso. La ejercitación propuesta tiene tres dimensiones, una conceptual, una geográfica, referida especialmente a las colonias helenas, y una referida a personajes fundamentales. La guía siete enfatiza en la época helenística y el imperio macedónico. En la primera se introduce la decadencia griega derivada de los conflictos entre Atenas y Esparta, que culminan con la Guerra del Peloponeso y latas disputas por la hegemonía que debilitan a la Hélade frente a persas y macedónicos. Estos últimos habrían terminado con la "libertad de Grecia", pero proyectaron la cultura helena hacia el Oriente, especialmente de la mano de Alejandro de Macedonia y "estos ejércitos de la raza helena" (Poblete, 1944b: 75-76). La guía termina con la dominación romana y está dividida en tres partes: Guerras civiles en Grecia, Imperialismo Macedónico y Época helenística. Aunque tiene una extensión menor que la anterior, mantiene complejidad y profundidad. Más allá de la mención al concepto "raza", no hay mayores referencias en ese sentido en esta guía, pero sí muestra un uso laxo del concepto, en la medida que se utilizó la palabra para denominar cuestiones tan diversas como la oposición entre semitas e indoeuropeos, la diferencia entre jonios y dorios, o la unidad de griegos y macedonios.

Finalmente, en la presentación de Roma hecha en la guía inmediatamente posterior, aparece una última referencia a la Hélade como un elemento fundamental de la corriente de la historia, cuestión que se asocia a la condición indoeuropea: "Después de conocer la historia de los pueblos orientales, llegó por fin a encontrarse con los pueblos griegos, primeros indo-europeos que estudió en detalle y que elaboraron una cultura que serviría enseguida de norma inspiradora a todo un continente" (Poblete, 1944b: 85). Si bien hay dos menciones a la condición indoeuropea de los griegos, la que una vez se opone a los semitas, y algunos usos del concepto "raza", no es posible identificar una formulación centrada en problemáticas raciales. De hecho, el ámbito racial tiene alguna relevancia dentro de las introducciones, donde el relato histórico se va conformando y tiene un evidente carácter eurocéntrico y civilizatorio. En ese relato se construyen férreos flujos históricos entre la antigüedad grecolatina y el 
Chile contemporáneo, que implican la inclusión de este último en la Historia. Esta se entiende como única y derivada inequívocamente de la antigüedad grecolatina, comprendida como occidental. De este modo, los indígenas precolombinos tienen un lugar previo a los griegos - prehistórico y precivilizatorio-, por lo que es posible suponer que la inclusión de Chile en la Historia está determinada por la colonización española. A su vez, ese rol los aleja de lo contemporáneo, a partir de una argumentación disciplinar que vincula lo antropológico, histórico y geográfico.

\section{4-1953: Pluralidad de civilizaciones y modernización de la enseñanza}

Junto con constatar el relato occidentalizante, es fundamental verificar también que en la misma guía este convive con el trabajo de ejercitación histórica, en el que se construye otra manera de relacionarse con la antigüedad. Tres elementos resultan centrales aquí: la ubicación temporal, la ubicación espacial y la búsqueda de información. Todos tienen un correlato claro con las habilidades declaradas por los objetivos del LMS para la enseñanza de los Estudios Sociales (Poblete, 1945, 153-155). Esto implica que la intención educativa de este cuadernillo supera la mera enseñanza memorística de un relato histórico, lo que va de la mano con la búsqueda por modernizar la enseñanza de la historia (Clío, 1943: 116). En ese sentido, también es posible encontrar una relación con la antigüedad que propicia un autoconocimiento mediante la ejercitación de habilidades complejas. En esta última dimensión, aunque con evidente diferencia en cantidad y profundidad de contenidos, los indígenas precolombinos y los griegos cumplen un rol similar: son un referente al que investigar, conocer y sobre el cual reflexionar y analizar. Esto implica un diálogo interesante entre el discurso disciplinar civilizatorio y su traducción pedagógica, en la medida en que esta última puede relativizar la teleología implicada en lo primero. De este modo, el dominio específico de la disciplina pedagógica aparece como relevante y distinguible del de la historia, en este caso. Esto dice relación con una creciente profesionalización del profesorado. En la búsqueda de modernización de la enseñanza de la historia, la aparición del documento Fuentes para el estudio de la historia antigua, de 1953, tiene un valor importante, pues muestra un afán explícito por avanzar en un sentido 
más centrado en el desarrollo de habilidades de los estudiantes. En ese sentido, el paso desde una lógica que proyecta un relato civilizatorio y evolucionista hacia el presente, a una que concibe la historia de forma más plural y enfatiza en la utilidad social de su enseñanza, es clarísimo y se ve refrendado por las reflexiones de la introducción y el prólogo. En este último, titulado "Dos palabras" y firmado por Juan Gómez Millas, se presenta el texto como una posibilidad de reconocer nuestra historicidad, pues permite "aproximarnos a esas vidas ajenas que debemos comprender para llegar a esclarecer el misterio que somos nosotros mismos" (Poblete, 1953b: 6).

En la introducción existen reflexiones en un sentido similar, vinculadas especialmente al propósito de la educación que, a la vez que establecen puentes con posiciones más espiritualizadas, también deslizan matices y diferencias con las mismas. Por ejemplo, a propósito de formas inadecuadas de enseñar la historia, se plantea lo siguiente en relación con la noción de "libertad":

"Abandonado así [el estudiante] a sus interrogantes sin respuestas, cae en el desaliento, en la negación para la acción, se refugia en el resentimiento y se convierte en campo propicio para todos los dogmatismos, en sujeto abonado para la diaria claudicación. Nunca, tal vez, se habló tanto de libertad. Cabe preguntarse cuánto hace de efectivo la función educadora por asegurarla y fortalecerla. No es la mera actitud de recuento, ni la curiosidad superficial las que deben llevarnos al conocimiento de la historia. Tampoco podemos caminar a través de ella a la manera confuceana, en pos de modelos ejemplarizadores para acomodar a ellos nuestras vidas y asegurar el orden social. Recordemos, como lo dice Jaeger, que "la estabilidad no es signo seguro de salud. Reina también en los estados de rigidez senil, en los días postreros de una cultura" (Poblete, 1953b: 8).

Hacia 1953 Olga Poblete ya era parte de disputas totalmente contingentes, entre las cuales la militancia por la paz era una cuestión fundamental. A nivel conceptual, una de las oposiciones centrales de la Guerra Fría era precisamente entre paz y libertad, siendo la primera cercana al lado soviético y la segunda a los Estados Unidos. Además, el vínculo entre la noción de "libertad" y la antigua Grecia fue trabajado en Chile por Jorge Millas o Fotios Malleros, y fue abundante en los dis- 
cursos del rectorado de Juan Gómez Millas. De este modo, las palabras de Poblete toman un sentido más complejo pues, al mismo tiempo que dialogan efectivamente con esas concepciones - por ejemplo, usando a la Paideia de Jaeger como referencia-, también denotan una cierta crítica a las actitudes más socialmente conservadoras. Por ende, se desliza lo problemático que resulta una suerte de impostación que, al mismo tiempo que afirma la defensa de la libertad, actúa de un modo contradictorio con su despliegue auténtico. Y este último aparece como intrínsecamente ligado a una lógica de autoconocimiento en la relación con la antigüedad griega:

"Muchas veces ha retornado el hombre a las fuentes helénicas, en demanda de esa fuerza inspiradora, cada vez con su propio bagaje de ideales y de esquemas de la realidad. Sin embargo, ha logrado volver enriquecido de este noble viaje, solamente cuando ha sido capaz, como el hombre griego lo hiciera en su tiempo, de elevar a primer plano su propia visión del mundo y del hombre, y de configurar una convivencia para expresar en toda la extensión de su significado y valor, la interpretación legítima de su realidad" (Poblete, 1953b: 8-9).

Ahora bien, también existe una suerte de proyección de los valores que se juzgan positivos para el presente hacia toda la población griega, pero resulta diferente a una concepción de lo griego como iniciador de una tradición occidental que impone los límites de lo posible para el momento. La concepción más pluralista de la civilización aparece con más claridad en la medida que afirma la existencia de algo así como una cierta "esencia humana", que trasunta en multiplicidad de productos de la creatividad del pasado. En ese marco, se igualan los pueblos antiguos, babilonios, chinos, indios, egipcios, hebreos, griegos o romanos. Por tanto, las diferencias que diez años antes los separaban bajo criterios raciales o civilizatorios se han diluido. ${ }^{21}$

21 Esto se reafirma con la publicación en 1955 de Tres ensayos sobre historia cultural china, en los que critica las "imágenes estereotipadas que arrancan de las vitrinas de los museos" y la facilidad de "presentar y asimilar el oriente a través del marco artificioso del exotismo que, a la larga, siempre nos deja el sabor de agradable de la superioridad de lo nuestro" (Poblete, 1955: 57). El llamado es, entonces, a conocer con profundidad la producción cultural y el desarrollo histórico chino, el cual califica incluso como "humanismo" (Poblete, 1955: 58). 
En cualquier caso, la presencia de lo griego sigue teniendo centralidad, aunque ya no como pueblo ario-indoeuropeo iniciador del Occidente. A la ya mencionada Paideia, se agrega una mención al modo socrático como el más adecuado para abordar el trabajo con documentos (Poblete, 1953b: 10). Esta búsqueda es conectada con las posibilidades que la historia brinda para la reflexión y el cambio: "Incorporemos a la función educativa, la vida propia de la historia y sintámosla transcurrir al calor de la discusión con las mentes juveniles" (Poblete, 1953b: 11). Acto seguido se reafirma la invitación al autoconocimiento, aunque ahora de forma algo más contingente: "No volvamos al pasado, como recurso para escapar del presente; tengamos la decisión de caminar con las imágenes del porvenir forjadas en la conciencia de las fuerzas que constituyen el proceso social del cual formamos parte" (Poblete, 1953: 11). Y se finaliza con un cierto posicionamiento político, en la medida que Pablo Neruda era notorio partícipe del Movimiento por la Paz, además de ser cercano al Partido Comunista: "Pienso en ellos [hombres y mujeres del mundo] y vuelvo a desear con mayor fuerza, que la juventud logre entender y realizar alguna vez plenamente, el significativo llamado del poeta de '... sube a nacer conmigo, hermano"' (Poblete, 1953b: 11). De este modo, aunque la pregunta por lo propio está respondiéndose a través del estudio de la antigüedad europea y asiática, la necesidad de responderla se ancla mucho más en la experiencia continental y nacional, en la medida que la cita al Canto General tiene una posición indigenista que, si bien no se incorpora en el texto de Poblete, sí parece reconocerse como significativa para el presente.

En buena medida, tanto por la igualación de los diversos pueblos de la antigüedad, por las referencias más ancladas en la necesidad de cambio y transformación, como por la mención al Canto General, es posible establecer un movimiento importante respecto de la guía previamente revisada. Pero tampoco existe un posicionamiento explícito y radicalmente crítico a dichas formulaciones de la Historia Universal, sino que todo lo contrario. La dimensión más política parece estar imbricada con un posicionamiento pedagógico e histórico, que se despliega en nombre de necesidades mucho más específicas y disciplinares. Es que, si bien ya existía una definición ideológica más o menos clara, la posición de Poblete en el campo era todavía endeble, pues especialmente en el ámbito institucional solo recientemente había sido incorporada como catedrática a la FFyE. 
1953-1962: Creciente politización y la pregunta por lo propio Este posicionamiento más subrepticio es mucho más claro a medida que pasa el tiempo, y también se despliega de modo más explícito en otros formatos. En efecto, en un artículo de la revista Educadores del mundo, de junio de 1956, Poblete revisa las discusiones sobre la reforma educacional en Francia. Se construye una oposición muy clara entre lo que sería una escuela para el porvenir y unas humanidades ancladas en el pasado:

"Una escuela empobrecida en sus contenidos, volcada al pasado antes que al porvenir, desvinculada de la realidad por la práctica mecánica del concepto clásico de las humanidades, ofrece el más fértil caldo de cultivo a las concepciones medioevales de la función educativa. Si justo en la edad de la máxima avidez intelectual del adolescente, de la más rica motivación para explorar el mundo material, social y cultural inmediato, la escuela desoye sus legítimos requerimientos, entonces, cómo sorprendernos de que busque en otros medios, bajo otras interpretaciones, aquellas realidades vivas que él, dramáticamente, intenta coger" (Poblete, 1956: 7).

A renglón seguido afirma que es natural la resistencia provocada por una escuela nueva, que tienda a la democratización de la vida colectiva mediante la promoción de la modernidad, la ciencia y el laicismo, pues ello implica el fin de un sistema para sectores sociales de Chile y Francia. En particular, dos intereses son explícitamente impugnados: las miradas clericales que aspiran a una actuación en el plano estrictamente espiritual, y las posiciones belicistas e irracionales que implican presupuestos exagerados para empresas militares en desmedro de la educación.

Un sentido similar puede encontrarse en el homenaje que Olga Poblete realiza a Gabriela Mistral en el marco del VI Congreso Americano de Educadores, a propósito de su muerte. Allí el enfoque está puesto en la figura de Mistral como artífice de la creación de lo nuevo $y$, por ende, como una suerte de maestra de los maestros, en la medida que su trabajo iluminó las posibilidades que entrega lo cotidiano. Ahora bien, también existe conciencia que "la escuela que ella soñó sigue aún aguardando el instante de alumbramiento" (Poblete, 1957: 23) y, por lo mismo, su carácter inspirador se hace aún mayor. En par- 
ticular, resulta muy interesante la relación que se establece entre la poeta y el sentimiento americanista asociado a la educación:

"volvamos los maestros de América a rebuscar entre las líneas cargadas de mensajes y recados, estos significados perennes de su creación magnífica. Seremos aún más leales a nuestra misión de educadores si allegamos nuestra tarea cotidiana a la magna obra de recuperación humana y cultural de nuestra América" (Poblete, 1957: 23).

Si bien no se explicita qué es aquello que se quiere recuperar del continente, es llamativo que dentro de la misma página en que se transcribe la alocución aparezca también un breve párrafo bajo el título "La moral incásica", que plantea lo siguiente:

"Los incas detestaban principalmente tres vicios humanos, estos eran: el hurto, la mentira y la holgazanería. En todo hogar había la obligación paternal de inculcar a los hijos la práctica de la honradez, de la verdad y del trabajo. La enseñanza constante de estos mandamientos, se expresaba en quechua: ama schua, ama llulla, ama k'ella, no robarás, no mentirás, no serás ocioso" (Poblete, 1957: 23).

El fragmento es de autoría del indigenista peruano Luis Valcárcel. Y, por lo mismo, existe una impronta de recuperación de lo indígena precolombino como una suerte de valor espiritual para el presente. Además, si es que leemos este fragmento a la luz de la mención a nuestra América en el discurso de Poblete, es posible pensar que efectivamente hay un llamado a conocer mejor lo propio, anclado en lo indígena. Es que el llamado de Martí (1891) en su célebre artículo es claro: "La historia de América, de los incas acá, ha de enseñarse al dedillo, aunque no se enseñe la de los arcontes de Grecia. Nuestra Grecia es preferible a la Grecia que no es nuestra. Nos es más necesaria". Esta posible valoración de lo indígena precolombino como potencia de lo propio puede reafirmarse a propósito de los Documentos para el estudio de la historia universal, publicado en 1962. Este libro consta de 28 documentos, cada uno de ellos con comentario y bibliografía. En la confección de este libro participaron varios estudiantes de Olga Poblete, práctica que también se replica en un libro posterior sobre la Historia Contemporánea. En cualquier caso, en Documentos... se 
incluye un apartado sobre "Historia de América y Chile", correspondiente a los documentos 17 a 28, lo que implica la inclusión de sendos espacios en la noción más amplia de Historia Universal. Los primeros dos documentos de este apartado corresponden a lo indígena precolombino, y es notoria la lejanía de las consideraciones primitivistas de décadas anteriores. Es más, junto con estos dos documentos hay otra mención de lo precolombino en el marco de la "Edad Moderna", dentro del documento 14, en que se presenta un fragmento del diario de Cristóbal Colón. Allí se menciona el encuentro con los "indios" a su llegada a la isla de Guanahani, y se describen los primeros intercambios desarrollados entre españoles y aborígenes. El documento finaliza con la siguiente afirmación: "Ninguna bestia de ninguna manera vide, salvo papagayos en esta isla" (Poblete, 1962: 53). Lo anterior implica una consideración de los nativos como humanos, y no como sujetos prehistóricos o bestiales. Ahora bien, en el comentario sí se manifiesta como posible utilidad del documento la de "establecer el contraste entre el grado de civilización que tenía el viejo mundo en esa época y la cultura de los pueblos aborígenes que habitaban el continente americano" (Poblete, 1962: 53). Aunque también se propone otro contraste en clave menos civilizatoria y más pluralista, como sería "percibir el paisaje con que se encontró el hombre europeo, al mismo tiempo que al aborigen, que poseía usos y costumbres muy diferentes a la de ellos" (Poblete, 1962: 53). En cualquier caso, en esta última propuesta todavía hay una suerte de mímesis entre el paisaje y quienes lo habitan. Y, además, el énfasis está puesto en la experiencia de los europeos, inclusive en el comentario se afirma que el documento prepara "el camino para tratar otros problemas de gran importancia, relacionados con la incorporación del Nuevo Mundo a la cultura europea" (Poblete, 1962: 53).

Más allá de constatar la existencia de perspectivas que todavía reproducen ciertas lógicas colonialistas, lo significativo en este caso es una mayor apertura en la noción de Historia Universal, cuestión que queda especialmente clara al incorporar la Historia de América y de Chile a dicho paraguas. En efecto, en tal capítulo se revisan otros documentos que sí ponen mayor énfasis en la vida de los indígenas americanos y en su grado importante de desarrollo para la época. El primer documento de esa sección se titula "Culturas autóctonas de América", y es un fragmento de la Historia verdadera de la Conquista de la Nueva 
España, de Bernal Díaz de Castillo. ${ }^{22}$ Allí se describe el mercado de Tenochtitlán, enalteciendo la cantidad de mercadería y de personas que allí transitaban. Existen al menos tres comparaciones con Europa, específicamente con Portugal, España, Roma y Constantinopla (Poblete, 1962: 65). En el comentario se explicita que la selección del documento tiene como intención propiciar el objetivo "Valorización de la Cultura Autóctona Americana" (Poblete, 1962: 66). Además, se plantea que el documento permite ilustrar cuestiones como el nivel de civilización alcanzado por las culturas precolombinas, enfatizando en su desarrollo material y económico, así como en los procesos históricos que llevaron a tales grados de progreso. También se plantean preguntas a propósito de inquietudes más contemporáneas: "Significado de la conquista española: arrasamiento de la cultura indígena y su reemplazo por la europea. ¿Qué conservamos aún de esta cultura autóctona americana?" (Poblete, 1962: 67).

El fragmento de los Comentarios reales del Inca Garcilaso de la Vega tiene un sentido similar, aunque más pronunciado en su valoración de lo precolombino. Se concibe al escritor como contemporáneo a los sucesos que describe, y se incluye en las materias "América precolombina" y específicamente "Grandes culturas precolombinas". En particular, mediante el documento se destacan los conocimientos incaicos en disciplinas como Geometría, Aritmética, Música y Geografía (Poblete, 1962: 68-69). Y el comentario enaltece más aún al Imperio Inca, pues se explicita que el propósito del fragmento es que los estudiantes reconozcan:

“el progreso extraordinario del lmperio lncásico, en síntesis, que obtengan de él conclusiones y observaciones inteligentes y que sean capaces de comprender o captar que un pueblo que siente afición por la música, que tuvo una Geografía y Geometría notables, que había regulado sus sistemas de contribuciones, tenía que ser, necesariamente, un pueblo evolucionado y poseedor de una cultura superior" (Poblete, 1962: 70).

Lo anterior se ve complementado con una consideración más político-administrativa del Imperio, dentro de la cual la noción de

22 Se cita la edición con notas y prólogo de Ramón Iglesias. México: Ed. Nuevo Mundo, 1943. 
"socialismo de Estado" aparece como central. De hecho, se propone la Unidad "El Imperio socialista de los Incas". Esta forma política es destacada en conjunto con lo que se concibe como el "legado de sus primitivos habitantes" para el moderno Perú. En torno a esto último, la relevancia incaica para el turismo y el folklore se destaca especialmente (Poblete, 1962: 70-71). Es interesante, en cualquier caso, que la noción de "primitivo" no parece tener en este caso una connotación evolucionista o civilizatoria, sino más bien refiere al hecho de ser habitantes pasados. En ese sentido, aunque tiene un carácter laudatorio y se construyen algunos flujos históricos entre antigüedad precolombina y contemporaneidad, la ruptura entre pasado y presente tiene gran peso. Por otro lado, la mención a Grecia en este mismo libro es muy diferente a las de 1953, en las que es posible encontrar múltiples formas de enaltecimiento del mundo helénico. En el texto de 1962 se incorpora solamente un documento y está referido a Esparta, específicamente un fragmento de la vida de Licurgo narrada por Plutarco en sus Vidas Paralelas. Allí se pone énfasis en el carácter militarista de la cultura lacedemonia, y se solicita al profesor realizar la siguiente advertencia:

"Corresponde al maestro advertir a los alumnos que si bajo este sistema alcanzaron algunas de las más elevadas cimas de la conducta humama, los espartanos sondearon también algunos de sus más profundos abismos. Todas las características de este sistema, materiales o espirituales, buenas o malas, estaban enderezadas a un único fin: el militarismo. Esparta se vio constreñida por este sistema de hierro en la unilateralidad del militarismo, y así el arte, y la ciencia le fueron imposibles" (Poblete, 1962: 26).

Lo anterior muestra una conciencia de los problemas que podría implicar el enaltecimiento de los espartanos en el momento contemporáneo, cuestión que había sido sumamente extendida en la Alemania nazi (Chapoutot, 2013). De hecho, se menciona que los espartanos tenían prácticas eugenésicas.

\section{Conclusiones}

A lo largo del artículo se dio cuenta de algunas transformaciones fundamentales del pensamiento de Olga Poblete a propósito de los conceptos de "historia universal", "antigüedad" y "civilización". Se propusieron cuatro factores como esenciales para comprender dichos cambios, y es 
posible establecer que existe una relación efectiva entre sendas partes. En efecto, entre 1932 y 1944 hay unas nociones de "historia universal" y "civilización" que se encuentran ancladas en miradas evolucionistas, universalistas, occidentalizantes, con visos de culturalismo y con presencia de ideas raciales. También existen evidentes jerarquías entre los pueblos antiguos, y los precolombinos son considerados como prehistóricos. Esto indica una posición subordinada dentro del campo, en el cual las posiciones políticas e ideológicas propias no parecen filtrarse en su trabajo académico, el que, a su vez, se encuentra anclado en perspectivas disciplinares que eran fuente de crítica por su necesidad de modernización. Ello es muestra de un contexto en el que la explicación de la historia mediante la apelación a la raza tenía un lugar relevante.

Entre 1944 y 1953 se vislumbra un cambio anclado en la crítica a las formas previas de enseñanza, lo que resulta especialmente claro en un uso más profuso de la documentación como forma de estudio de la historia que abunda al finalizar este momento. Además, existe una concepción más plural de las civilizaciones y de la historia universal, lo que se proyecta en una desjerarquización de los pueblos antiguos, lo que parece de alguna manera anclado en sus posiciones políticas e ideológicas. Esto es especialmente claro para el caso de China. Por otro lado, la capacidad de mayor agencia que parece existir en su desenvolvimiento académico resulta derivada de una posición en el campo más sólida, cuestión coronada con su incorporación como catedrática a la universidad.

Entre 1953 y 1962 aparece una concepción más pronunciadamente política de la historia universal y la civilización, en la cual la pregunta por el lugar de América Latina, dentro de ese marco, parece tener una mayor relevancia. Además, es claro que hay una búsqueda por relevar formas culturales desdeñadas previamente, como son las culturas precolombinas. Junto con ello, el lugar de los griegos como referente de Occidente ya no está presente. Esto debe comprenderse en un contexto de creciente politización, que coincide con un lugar más consolidado en el campo. De hecho, con posterioridad a este estudio y durante la Unidad Popular, existirán otros Documentos para el Estudio de la Historia Universal publicados por Olga Poblete, en los que el lugar de los pueblos colonizados y la búsqueda por valorar su pasado y producción 
cultural resultan todavía más pronunciados. En ellos, la América precolombina se incorpora al periodo de la "Edad Moderna", lo que indica un cambio completo de criterio respecto de la década del cuarenta. Es valioso reconocer y estudiar estos tránsitos, especialmente porque el golpe de Estado de 1973 implicó fuertes retrocesos en estas formas de concebir la historia, lo cual tiene repercusiones hasta el presente. Por lo mismo, poner en valor este tipo de trayectorias historiográficas e intelectuales enriquece el conocimiento de nuestra disciplina y abre espacios para una reflexión más profunda sobre la relación entre historia y política. Junto con lo anterior, también es necesario destacar que reconocer las transformaciones en las relaciones que se construyen entre antigüedad, historia universal y civilización permite enriquecer el conocimiento actual sobre la historia de dichos conceptos y las maneras en que han operado en América Latina.

Por otro lado, este estudio busca pensar a Olga Poblete en relación con una tradición de pensamiento crecientemente, como sería la anticolonial. Esto busca no solo enaltecer su compromiso político, sino también mostrar las relaciones entre este y su trabajo intelectual, concibiendo este último como un lugar transformador y colectivo. Pero, por cierto, dichas intenciones también tienen una dimensión problemática, especialmente cuando el enaltecimiento de procesos concebidos como liberadores en la época termina siendo contradictorio con la promoción de los derechos fundamentales, cuestión que formaba parte de su tarea como militante por la paz. En efecto, la visión acríticamente positiva de China, Corea del Norte o la Unión Soviética, que puede encontrarse en parte de sus intervenciones más políticas, resuena problemáticamente hoy. Será fundamental, entonces, continuar estudiando y profundizando en el pensamiento de Olga Poblete, para ponderarlo de forma más integral.

Finalmente, resulta interesante hacer notar que la militancia feminista no traspasa de forma palmaria la barrera entre lo político y lo académico. En las colecciones documentales revisadas no se han encontrado aún textos centrados en la condición femenina, mientras que las problemáticas de la paz y de la guerra sí están más presentes. Una razón posible para ello podría ser que su consolidación como figura más o menos relevante en la intelectualidad chilena es posterior a la desaparición del MEMCH, momento para el cual su involucramiento 
político estaba más centrado en la militancia por la paz. Pero si se mira con agudeza, es posible encontrar pistas que muestran que el feminismo es una perspectiva presente en su pensamiento y trabajo. El final de su carrera académica a manos de la dictadura impide saber si con una posición más consolidada y dominante, que le otorgara una mayor libertad, el feminismo habría sido más central en su obra.

\section{Referencias bibliográficas}

Fuentes primarias

\section{a) Publicaciones periódicas}

Clío (1943). “Temas y resoluciones del Primer Congreso Nacional de Estudiantes de Pedagogía" en Clío, Vol. 10, N 13-14, pp. 100-157.

Glavic, N. (1944). "Los centros de estudios" en Boletín del Liceo Experimental Manuel de Salas, Año I, № 2, pp. 49-54.

Mistral, G. (1950). "La palabra maldita". Recuperado de http://www. gabrielamistral.uchile.cl/prosa/palmaldita.html, revisado el 10-I-2021

Poblete, O. (1930). “En busca de un hombre”, en Índice, Año 1, No 5, pp. 12-13.

Poblete, O. (1933a). "Historia antigua del extremo oriente: India, China, Japón y Asia Central”, en Clío, № 1, pp. 25-32.

Poblete, O. (1933b). "Historia antigua del extremo oriente: India, China, Japón y Asia Central (continuación)," en Clío $\mathrm{N}^{\circ}$ 2, pp. 9-14.

Poblete, O. (1944a). "Antecedentes de los centros de estudio y algunas de sus actividades", en Boletín del Liceo Experimental Manuel de Salas, Año I, $\mathrm{N}^{\circ} 2$, pp. 55-58

Poblete, O. (1945). “Objetivos de los estudios sociales", en Boletín del Liceo Experimental Manuel de Salas, Nㅜ 3, pp. 153-155.

Poblete, O. (1956). "El problema de la escuela laica en profesores de Francia", en Educadores del Mundo, № 2, pp. 5-7.

Poblete, O. (1957). "VI Congreso Americano rinde homenaje a Gabriela Mistral”, en Educadores del Mundo, N 5, p. 23.

Poblete, O. (1980). "Homenaje a Hernán Ramírez Necochea”, en Araucaria de Chile, $\mathrm{N}^{\circ} 9$. 
b) Libros, documentos e impresos

Martí, J. (1891). Nuestra América.

Poblete, O. (1944b). Guías de Estudio y Ejercicios, correspondientes al programa de Historia y Geografía del IV año de Humanidades, Santiago, Chile: Prensas de la Universidad de Chile.

Poblete, O. (1951). Carta a Gabriela Mistral, (Santiago, Chile a Nápoles, Italia), 9-XI-1951.

Poblete, O. (1953a). Hablemos de China nueva. Santiago, Chile: Vida Nueva.

Poblete, O. (1953b). Documentos para el estudio de la Antigüedad. Santiago, Chile: Universidad de Chile, Liceo Manuel de Salas.

Poblete, O. (1955). Tres ensayos sobre historia cultural china: para una mejor comprensión de nuestros vecinos de la ribera del pacífco. Santiago, Chile: Universitaria.

Poblete, O. (1962). Documentos para el estudio de la historia universal. Santiago, Chile: Universitaria.

Poblete, O. (1990). Dr. Alejandro Lipschutz. Cuatro conferencias sobre su labor en el área de la antropología social. Santiago, Chile: Fondo Olga Poblete, Archivo Nacional, Chile.

Poblete, O. (1991). La guerra, la paz y los pueblos. Santiago, Chile: Tácora.

\section{Fuentes secundarias}

a) Artículos y capítulos de libros

Ahumada, M. (2020). “Viajeros a la República Popular China: José Venturelli, los intelectuales, políticos y parlamentarios chilenos en los años cincuenta y sesenta", en Transmodernity: Journal of Peripheral Cultural Production of the Luso-Hispanic World, Vol. 9, N 3, pp. 6-33.

Chakrabarty, D. (2008). "La poscolonialidad y el artificio de la historia", en Al margen de Europa. Pensamiento poscolonial y diferencia histórica. Barcelona: Tusquets, pp. 57-81.

Gazmuri, S. (2016). "La lectura de los autores romanos y la construcción del discurso republicano: citas, traducciones y adaptaciones. Chile, 1810-1833", en Historia, Vol. 49, № 2, pp. 429-453.

Grosse, F. (2017). "Arnold Toynbee. América Latina y las civilizaciones", en Cuadernos del CEL, $\mathrm{N}^{\circ}$ 3, pp. 209-215. 
Huidobro, M. G. (2018). "Classical tradition and republican ideals for the independence of Chile", in Classical Receptions Journal, Vol. 10, $\mathrm{N}^{\circ} 1$, pp. 21-39.

Jiles, X. y C. Rojas (2019). “La extraordinaria acción política protagonizada por el Movimiento proEmancipación de las Mujeres de Chile (MEMCH), 1935-1949", en M. Loyola; A. Comandini y R. Álvarez (Eds.) Mujeres y política en Chile. Santiago, Chile: Ariadna, pp. 157-188.

Kozel, A. y H. Taboada (Eds.). (2017). "América Latina como civilización" Dossier en Cuadernos del CEL, Vol. II, № 3.

Méndez, L. M. (1984). "La mujer y la historiografía chilena" en Revista Chilena de Historia y Geografía, № 152, pp. 157-177.

Neut, S. (2018). "Control ideológico en los programas secundarios transitorios en Historia y Ciencias Sociales (1974-1981)", en Educação e Pesquisa, Vol. 44, pp. 1-18.

Poblete, O (1983). "El MEMCH, un capítulo del militantismo femenino chileno", en Araucaria de Chile, $\mathrm{N}^{\circ}$ 24, pp. 160-167.

Riobó, E. y D. Smith. (2019). “Civilización: genealogías e historias de una noción", Dossier en Pléyade, $\mathrm{N}^{\circ} 23$.

Riobó, E. y F. Villarroel. (2019). "Belleza plástica, eugenesia y educación física en Chile: presentación de la fuente 'Aspectos de la educación física,' de Luis Bisquertt (1930)", en História, Ciências, Saúde - Manguinhos, Vol. 26, Nㅜㄹ, pp. 673-682.

Sánchez, M. y E. Riobó. (2020). “Griegos, latinos y germanos en algunos escritos racistas y eugénicos chilenos de la primera mitad del siglo XX", en Historia, Vol. 53, № 1, pp. 183-210.

Soler, L. y C. Valenzuela. (2020). "Representación y (re) significación de un héroe moderno. Caupolicán en las retóricas clásicas y nacionalistas", en Boletín Americanista, Año LXX, Vol. 2, No 81, pp. 177-199.

Stecher, L. y N. Cisterna. (2020). “Heraldo de la Mujer de Ana Roqué: estrategias de posicionamiento en la lucha sufragista puertorriqueña", en Estudios Filológicos, $N^{\circ} 64$, pp. 35-51.

Taboada, H. (2012). "Los clásicos entre el vulgo latinoamericano", en Nova tellus, Vol. 30, № 2, pp. 205-219,

Taboada, H. (2014). “Centauros y eruditos. Los clásicos en la independencia”, en Latinoamérica, $\mathrm{N}^{\circ}$ 59, pp. 193-221. 
Toro, P. (2018). "Una nueva oficina en el liceo: la instalación de los orientadores como política educacional en Chile (c.1946c.1953)", en Historia Caribe, Vol. 13, №33, pp. 281-313.

Villalobos Martínez, A. (2016). "Aportaciones del mundo clásico al discurso humanista en Chile (1910-1970)", en Tiempo y espacio, Vol. 34, pp. 61-85.

Villar Vásquez, G. (2020). “La Universidad de Chile según el académico y militante comunista Hernán Ramírez Necochea (19601964)", en Cuadernos de Historia, $N^{\circ}$ 53, pp. 113-143.

Viveros, A. F. (2020). “¿Modelos clásicos como patrimonio cultural público? Arquitectura y escultura en Santiago y Buenos Aires (1850-1920)", en Córima, Revista de Investigación en Gestión Cultural, Vol. 5, № 9, pp. 1-24.

b) Libros

Albuquerque, G. (2011). La trinchera letrada, Santiago, Chile: Ariadna.

Antileo, E. (2020). ¡Aquí estamos todavía! Anticolonialismo y emancipación en los pensamientos políticos mapuche y aymara (Chile-Bolivia, 1990-2006). Santiago, Chile: Pehuén.

Bergel, M. (2015). El Oriente desplazado. Los intelectuales y los orígenes del tercermundismo en la Argentina. Bernal: Universidad Nacional de Quilmes.

Bourdieu, P. (1997). Razones prácticas. Sobre la teoría de la acción. Barcelona: Anagrama.

Castillo Didier, M. (2015). Pensando Grecia, pensando América. Santiago, Chile: Centro de Estudios Griegos y Ediciones Tácitas.

Chapoutot, J. (2013). El nacionalsocialismo y la antigüedad. Madrid: Abada.

Galdames, F. (1955). Luis Galdames. Historiador, educador, escritor. Memoria de prueba para optar al título de profesor de Estado en Historia, Geografía y Educación Cívica. Santiago: Universidad de Chile.

Greenwood, E. (2010). Afro-Greeks. Dialogues between Anglophone Caribbean Literature and Classics in the Twentieth Century. Oxford: Oxford University Press.

Hardwick, L. y C. Gillespie (2007). Classics in postcolonial worlds. Oxford: Oxford University Press. 
Jiles, X. y C. Rojas (2017). Epistolario emancipador del MEMCH: Catálogo histórico comentado (1935-1949). Santiago, Chile: Archivo Nacional.

Mansilla, L. (2010). Gente del siglo XX. Santiago, Chile: LOM.

Pizarro, A. (2004). El sur y los trópicos. Ensayos de cultura latinoamericana. Alicante: Universidad de Alicante.

Taboada, H. (2017). Extrañas presencias en nuestra América. Ciudad de México: Centro de Investigaciones sobre América Latina y el Caribe, Universidad Nacional Autónoma de México.

Valenzuela Matus, C. (2016). Grecia y Roma en el Nuevo Mundo. La recepción de la antigüedad clásica en cronistas y evangelizadores del siglo XVI americano. Barcelona: Ediciones Rubeo.

Zapata, C. (2013). Intelectuales indigenas en Chile, Bolivia y Ecuador. Diferencia, colonialismo y anticolonialismo, Quito: Abya Yala.

Vlassopoulos, K. (2007). Unthinking the Greek Polis: Ancient Greek History beyond Eurocentrism, Cambidge: Cambridge University Press.

c) Otros

Andújar, R. (2020). Encuentros latinoamericanos con la antigüedad grecolatina: teoría, desafios y oportunidades. Conferencia inaugural. Maestría de Estudios Clásicos, Universidad de los Andes, Colombia. Recuperado de https://facartes.uniandes. edu.co/evento/conferencia-inaugural-de-la-maestria-enestudios-clasicos-de-la-universidad-de-los-andes-rosa-andujar/, revisado el 10-I-2021.

Sánchez, M. (2016). "Las antigüedades del pequeño dictador. Los imaginarios de lo antiguo en Geopolítica de Augusto Pinochet". Presentación oral realizada en la II Jornada de Humanidades: El Mundo Clásico y su trascendencia en la actualidad. Pensando a los Clásicos para Latinoamérica, realizada el 28, 29 y 30 de noviembre de 2016.

Sitio web del Archivo Nacional, "Natalicio de Olga Poblete, profesora de la paz y el feminismo". Recuperado de https://wwwarchivonacional.gob.cl/616/w3-article-86872.html?_noredirect $=1$, revisado el 10-I-2021.

Youtube, "Capítulo 5: Mujeres Chilenas - La Historia Secreta de Chile 2". Recuperado de https://www.youtube.com/ watch?v=gNJjckpARTg, revisado el 10-I-2021. 
Youtube, "Material de Cámara. Entrevista a Olga Poblete y Elena Caffarena $2^{\text {a }}$ parte. 1989. Diamela Eltit". Recuperado de https:// www.youtube.com/watch? $\mathrm{v}=\mathrm{OykVsebxgSc} \& \mathrm{t}=2 \mathrm{~s}$, revisado el 10-I-2021.

Youtube, "Material de Cámara. Entrevista a Olga Poblete y Elena Caffarena $3^{\text {a }}$ parte. 1989. Diamela Eltit". Recuperado de https:// www.youtube.com/watch?v=nfTUppZvQ1k\&t=813s, revisado el 10-I-2021. 